\title{
Carlos A. Scolari
}

\section{Lostology: Transmedia storytelling and expansion/compression strategies}

\begin{abstract}
The objective of this article is to analyze Lost from the perspective of transmedia storytelling and to propose a taxonomy of transmedia expansion/ compression strategies. In the first section, the article presents the basic components of transmedia storytelling from a theoretical point of view that combines narratology and semiotics. After describing the most important components of Lost's transmedia fictional universe in the second section, the article presents a general description and taxonomy of expansion/compression narrative strategies based on traditional rhetorical categories. The article also analyzes "compressed texts" - like recapitulations - and their role inside the expansive strategies.
\end{abstract}

Keywords: Lost; transmedia; storytelling; narrative; strategy; user-generated contents

Carlos A. Scolari: Universitat Pompeu Fabra. E-mail: carlosalberto.scolari@upf.edu

Lost can be considered one of the best examples of multichannel, multiplatform, complex narrative produced in the first decade of the twenty-first century. Like any other complex phenomena - Lost is not just another TV show - it can be approached from different perspectives. In recent years scholars have analyzed this transmedia narrative experience from a broad spectrum of perspectives: audience-building and consumption practices (Abbot 2009; Brooker 2009; GonzálezAlarcón and Anyó 2009), branding and marketing (Cascajosa 2006; Johnson 2009; Grainge 2009), narrative (Gómez Alonso 2008; Askwith 2009; Clarke 2009; Lavery 2009; Mittel 2006, 2009; Pearson 2009), genre (Tous 2010), religion (Ankerberg and Burroughs 2007), video games (Jones 2008), and, last but not least, transmedia storytelling (Hill 2006; Ndalianis 2009; Smith 2009). Among the many possibilities offered by Lost, in this article I will analyze this production from a perspective that combines narratology and semiotics, and I will propose a taxonomy of expansion/compression narrative strategies based on traditional rhetorical categories. 


\section{Towards a theory of transmedia narratives}

In an interview published in Wired magazine (1997) George Lucas evidenced the distance between media: for him cinema is one thing, and video games, something completely different.

- Movies are storytelling; you tell somebody a story. A game is interactive; you participate in some kind of an event with a lot of other people or with yourself, or with a machine. Those are two different things, and they've been around here forever. Games have been here since the Greeks, and so has storytelling.

- You don't think that those two are going to cross over at all?

- $\quad$ No! Because by definition they are different - storytelling and games are two different mediums. (Kelly and Parisi 1997)

Twenty-first century convergence processes (industrial convergence, professional convergence, technological convergence, and narrative convergence; Scolari 2008a; Dwyer 2010) have completely changed the landscape. Today convergence is one of the key concepts for understanding what's happening in the media ecology. In this article I'll focus on media narrative convergence, or in other words, transmedia storytelling.

\subsection{Transmedia storytelling}

What do we mean by transmedia storytelling? According to Jenkins (2003, 2006b, 2009 , 2011) many contemporary works are characterized by expanding their narrative through different media (film, TV, comics, books, etc.) and platforms (blogs, forums, wikis, social networks, etc.). For example, the Fox series 24 began as a TV show but ended up including mobisodes, webisodes, video games for consoles, mobile games, comics, novels, board games, and a plethora of official and fan websites (Scolari 2009a). We can add a second feature to this cross-media dimension of storytelling evidenced by Jenkins: the creation of user-generated contents. Transmedia narratives begin in a Hollywood studio or in the comic book editor's office in Manhattan but continue, for example, in a blog written by a Finnish girl or in a parody video uploaded onto Youtube by a group of Brazilian fans. Thanks to Jenkins the concept of transmedia storytelling has already been accepted in the academic environment, although in the professional world many producers prefer to talk about cross-media. In this article I'll consider the two terms as synonyms. 
Jenkins expanded traditional media studies when he incorporated the concept of transmedia storytelling and focused his research on user-generated content and the prosumers' experiences (Jenkins 2006a). But there are other possible doors into the study of transmedia storytelling. In this article I propose an approach inspired by contemporary narratology (from Propp to Genette) and semiotics, with specific references to the Italian (Eco 1979) and French schools (Greimas 1987). As ethnographic research examines the users' productive activities, the semio-narrative approach concentrates on the textual level of transmedia narratives. From this theoretical perspective we could say that the origin of a narrative is almost a secondary problem: it is not so important who produces a text (it could be a Hollywood studio or a fan) but rather how the texts are articulated and integrated into a complex narrative system. In this context I'm not proposing a complete semio-narrative analysis of Lost: that would be almost impossible to achieve in a single article. The article, then, is focused on a general level, that is, the analysis of the transmedia textual macro-space and how transmedia narrative strategies develop inside this environment.

According to Roig "transmedia narrative involves designing and creating its own universe, complex and consistent enough to facilitate the recognition and the consistency across different media forms" (2010: 245). The semio-narrative approach is one of the best possible tools for analyzing this textual complexity and narrative consistency.

Transmedia narrative worlds are a real challenge for communication studies, in particular for narratology and semiotics. Like most media studies, narratology and semiotics have also proposed monomediatic approaches. We have many specific semiotics (semiotics of radio, semiotics of television, semiotics of cinema, semiotics of theater, etc.) but we don't have a semiotics of transmedia experiences. Narratology and semiotics are unaccustomed to analyzing highly complex multimodal narratives characterized by textual fragmentation and dozens of characters and narrative programs that inhabit different media and platforms (Scolari 2008b, 2009b, 2009c). George Lucas was partially right: cinema and video games are different media. However, now narratives and media are converging, and we can no longer analyze them in isolation from each other.

\subsection{User-generated contents}

Even if content production by consumers has always been present in the culture industry, the digitization process, the dissemination of graphic user interfaces which facilitated the handling and recombination of all types of texts - and the advent of the World Wide Web totally changed the game rules. Digitized texts 
have become malleable and susceptible to being remixed with other contents (Scolari 2008a, 2009b). The web, especially social networks and open platforms such as Youtube, has accelerated the viral circulation of contents around the world. This is the breeding ground of user-generated contents.

As I'll demonstrate in section 2.3, the borderline between user-generated contents and the culture industry's production is very porous. Contents born on the margins may end up being taken over by large communication systems, in the same way that the culture industry pays close attention to the prosumer's productions and has no scruples about distributing these contents and even making a profit from them.

\subsection{Expansions and compressions, fiction and non-fiction}

In a recent publication on the mutation of television, Barra et al. (2010) proposed three dimensions for analyzing the convergence process: extension, access, and branding. In this article I'll focus on the first of these: extension. When we talk about transmedia storytelling we usually refer to the expansion of a narrative world through different media and platforms. However ... Are all transmedia experiences "expansive”? Are there any experiences of "narrative compression"? Many audiovisual contents, rather than expanding the story, reduce it to a minimum expression, like in trailers and recapitulations. The collision of old and new media has produced a large number of textual splinters, and may be the best expression of what has been defined as snack culture (Miller 2007). Even if they do not incorporate new characters or their narrative programs are very limited, these paratextual nanotexts provide new interpretation frames or allow the consumer to enter the narrative world, and therefore become a basic component of the transmedia universe (Gray 2009: 3).

In other words, if we consider that transmedia narratives can only be expansive, then many paratextual productions would fall outside the limits. If, however, we adopt a more flexible definition of transmedia storytelling, these compressed contents should also be analyzed as part of the fictional world. Moreover, the fact that many of these nanocontents are user-generated and circulate in social networks like Youtube reinforces the idea that they should be included in a study of transmedia storytelling. I'll return to this issue in Section 2.4 when I analyze Lost recapitulations, and also in the Conclusions.

This article is dedicated to crossmedia extension/compression strategies. Smith (2009) described transmedia extensions in the form of new episodes, diegetic artifacts or alternate reality; Dena (2008a) proposed three types of multiplatform expansion (series, serials, and hybrids), and Long (2007) classified 
transmedia stories based on how they were first conceived (hard, soft, and chewy transmedia narratives). In this article I'll describe the extension/compression strategies and arrange them according to rhetorical principles.

Finally, every time scholars talk about transmedia storytelling the discourse is centered on fictional characters and stories (Harry Potter, Indiana Jones, The Matrix, 24, Lost, etc.). We should remember that transmedia storytelling is not just fiction. Advertising has been a transmedia experience since the explosion of mass media in the first half of the twentieth century, and the same can be said about journalism in the second half. Non-fiction transmedia storytelling is still an unexplored territory waiting for its explorers.

\section{The transmedia fictional world of Lost}

Lost was first broadcast on September 22, 2004 on the ABC (American Broadcasting Company). The first season consisted of twenty-five episodes, and the first one was double. The number of episodes decreased over the years (twenty-four in the second season, twenty-three in the third, fourteen in the fourth, seventeen in the fifth, and eighteen in the sixth and final season). However, the reduction in the number of episodes was balanced by the creation of additional contents in other media and platforms.

The first four seasons remained among the top twenty US ranking, while the last two fell to lower positions. In its first two seasons Lost attracted more than eighteen million viewers, this fell to thirteen million in the third season, to twelve in the fourth and remained at about ten million viewers in the last two seasons. In spite of this, the series was one of the first shows to be available in the iTunes Store for legal downloading. However, the episodes can be seen with commercial breaks included on the ABC's website and on many other TV channels' webpages around the world. In December 2008 the Nielsen agency declared that Lost was the most-watched series on the web with 1,425 million viewers (Whitney 2009). Lost's DVDs have also been very well received by audiences and have achieved high sales. ${ }^{1}$ Obviously this legal market data need to be completed with the millions of illegal downloads that have been made throughout cyberspace. But the fictional world of Lost does not end with these television products: it has spread to other media and communication spaces to become one of the most comprehensive and interesting transmedia narratives of the first decade of the twenty-first

1 Wikipedia contributors, “Lost (TV Series)," Wikipedia, http://en.wikipedia.org/wiki/ Lost_\%28TV_series\%29 (accessed 1 March 2013). 
century. In this article I could only map a small portion of Lost's fictional world; I will focus on the novels, video games, comic books and audio-visual contents, especially those diffused on the web. For reasons of space many other interesting contents which are very important for understanding the narrative world of the series - such as Lostpedia ${ }^{2}$ or the Lost University ${ }^{3}$ - will not be discussed here.

\subsection{Books and webs}

Lost generated a series of novels based on the life of some survivors of the tragic Flight 815 from Sydney to Los Angeles, which establish strong intertextual links with the TV show on a narrative level. These novels also include the typical flashbacks of the series, introducing another intertextual connection, but on a discursive level.

The novels are the following:

- Hapka, Cathy (2005) Endangered Species. The main character is Faith Harrington, an environmentalist who was on Flight 815. Throughout the story Faith interacts with all the TV characters of the first season.

- Hapka, Cathy (2006) Secret Identity. Hapka's second novel tells the story of Dexter Cross, a college student who led a double life before the accident.

- Thompson, Frank (2006) Signs of Life. This book tells the adventures of Nick Hadley, an artist in crisis who survives the Flight 815 crash. While on the island this artist resumes his production but it becomes imbued with a sinister, apocalyptic tone. The fourth novel differs significantly from the previous texts because of its metanarrative characteristics:

- Troup, Gary (pseudonym of Laurence Shames), Bad Twin. In the first episode of the TV series, a few minutes after the tragic accident, an image shocked the viewers: a survivor walking on the beach was literally sucked into the turbine of the plane generating a blast and adding new victims to the list. Lost's followers discovered later that "the man of the turbine" was a writer called Gary Troup. Among the "Easter eggs" and interpretative keys of Lost's fictional world we must include Gary Troup's name, which is an anagram of the word Purgatory.

2 http://lostpedia.wikia.com (accessed 1 March 2013)

3 http://www.lostuniversity.org (accessed 1 March 2013) 
In the episode "The Long Con" (season 2, episode 13) the manuscript of his latest book entitled Bad Twin is found by Hugo "Hurley" Reyes in the wreckage of the plane. In "Two for the Road" (season 2, episode 20) the text reappears in the hands of James "Sawyer" Ford, but Jack Shephard destroys the manuscript before he finishes reading it. Bad Twin is a novel riddled with references to the TV show. The central character of the manuscript is Paul Artisan, a private investigator hired by Clifford Widmore to find his identical twin brother, Alexander. They are obviously rich members of the Widmore family that appears in the TV series.

During the first season the ABC's official website published a diary written by a survivor never seen on TV called Janelle Granger. This weblog repeated the pattern of the literary works mentioned above: it told the story of a survivor who interacts with the characters already seen on the TV screen.

The creation of peripheral webs that are interwoven with the fiction that unfolds on TV deepened with the emergence of the "official" websites of Oceanic Airlines, Hanso Foundation, and Dharma Initiative, the latter two of which are closely linked to the mysterious island. In November 2005, the ABC started a weekly podcast with interviews and discussions. However, this web has always served as a channel for legal or illegal dissemination of the episodes and other contents like trailers, promos, recaps, and other paratexts designed to promote the series.

But it was in the two Alternate Reality Games (ARGs) where the use of the web actually exponentially enhanced the narrative world of Lost. The Lost Experience was co-produced by the ABC (USA), Channel 7 (Australia), and Channel Four (UK) at the end of the second season (2006). The game included commercials, hidden information on the "official" websites mentioned above, videos, passwords, and even Apollo chocolate bars (a fictional brand that appears in several episodes). The online discussion forums were the natural setting for solving the riddles and questions posed by The Lost Experience. The second ARG was entitled Find 815 and was implemented in January 2007, just before the start of the fourth season. Unfortunately, a complete description of Lost's ARGs is not possible in this article, but if transmedia storytelling is one of the most interesting objects of contemporary media research, ARGs should be considered the icing on the cake (Jones 2007; Dena 2008b; Abba 2009; Kim et al. 2009). Many of these transmedia experiences - from the Oceanic Airlines website to the complex network of contents of the ARGs - are situated in that borderland where marketing strategies blend into fictional worlds (and vice versa). As I explained before, transmedia storytelling is not only about fiction: cross-media experiences may be found in journalism, documentaries, and advertising, and sometimes combined with fictional narrative worlds. 


\subsection{Mobile and video games}

Lost: Missing Pieces is a series of thirteen short videos that run for one to four minutes, produced for mobile phones and distributed between November 2007 and January 2008. While the original plan was to keep the logic of the novels (to narrate the misfortunes of other survivors never seen in the TV show) after many delays the producers decided to work with the characters already known to the public.

In these mobisodes the TV characters interact in situations that complement what has already been seen on the small screen. This type of content can be called interstitial (Scolari 2009a) because it fills narrative gaps that in the original story had disappeared into the logical ellipses of the plot. As a "fill in the blanks" grammar exercise, the producers created these mobisodes to fill those little empty spaces and contribute to the construction of the general sense of the story. Except for one of them - made with original recordings from the TV show - the rest of the Lost: Missing Pieces mobisodes were specifically produced to be distributed on mobile devices.

In terms of games, Lost promoted a series of products ranging from Lost: Via Domus, a video game developed by Ubisoft in 2008 for consoles and computers, to board games, puzzles, and trading cards (Lost: Revelations). In 2006, Gameloft had already launched a video game for mobile phones and iPods inspired by the TV series. From a transmedia narrative perspective Lost: Via Domus is the most important of all the games.

Instead of "levels" Lost: Via Domus offers the player seven "episodes" that develop over the first seventy days after the accident. The user plays the role of Elliott Maslow, a survivor of Flight 815 never seen on the small screen. Throughout the episodes the player/Maslow interacts with the main characters of the series and visits different Dharma stations and places of the island well-known to TV audiences. Maslow suffers from amnesia but has flashbacks to help him rebuild his past.

As we can see Lost: Via Domus is seamlessly integrated into Lost's transmedia strategy as it not only brings new characters, narrative programs and relationships with other survivors but maintains the use of flashbacks, one of the hallmarks of the TV show. In terms of its autonomy in relation to the TV series, any player can enjoy Lost: Via Domus but obviously the fans of the TV show have many more elements to understand the situations that arise in the game. In Eco's terms the players who have watched the TV show have a larger encyclopedia (Eco 1979), which permits them to better interpret and enjoy the video game. Like any other video game Lost: Via Domus also generated an online community of users that facilitated the exchange of experiences and tips for advancing in the game (Jones 2008: 20). 


\subsection{Comics and action figures}

Pardillos is a webcomic created by the Spanish student Carlos Azaustre that follows the events of Lost's TV seasons step by step. The first webcomic was released in 2007 after a promotional trailer that announced its arrival. The author introduced his particular version of the story on the blog:

When parody overcomes fiction ... February 30, 2004. An airplane of Naufragic Airlines starts the Flight 3.1415 from Ibiza Island to Cuenca. The flight never arrives to its destination. In the midst of the journey a fatal accident causes the plane to crash on a mysterious island in the Mediterranean Sea. Fourteen survivors, including a doctor, a butcher boy-scout, a fugitive, a spunky, a robot, a video game geek, a pregnant girl ... will face many dangers and will have to survive on the island.

Why "Pardillos"? The title of the webcomic is just part of the parodic spirit of the story. In Spanish Lost is translated as Perdidos, from which we arrive to Pardillos, the Spanish word for bumpkin, yokel. Azaustre continued the publication of his parody on the web until 2008, when he decided to take the big step and print it. As the publishers refused, he compiled the first season's comics and self-released the volume Pardillos: Primera Temporada (Pardillos: First Season). A few months later the volume was available at major book stores in Spain. In 2009, coinciding with claiming the prize for Best On-Line Comic at the Comic Exhibition in Madrid, the third album was released. The forth and fifth albums arrived in 2010. By the end of 2010 Pardillos had sold over 15,000 copies.

Pardillos is a comic in which the fictional world of Lost (its characters, their narrative programs, the relations between them and the sequence of events triggered on the island) is reinforced by a complex intertextual network of links with contemporary Spanish popular culture. The parody is not only in the jargon used by characters or in the transformation of their names (i.e., John Locke $\rightarrow$ Yon Locko) but in the intertextuality that does not hesitate to poke fun at the island's TV show hosts and reality show contestants very well-known to the Spanish public.

A couple of examples show this intense intertextual game. During the first season the Iraqi Sayid Jarrah (an ex-torturer in the Republican Guard of Saddam Hussein and telecommunications expert, represented in the comic as a robot) meets Danielle Rousseau, the only survivor of a French expedition that sank off the island sixteen years earlier. In Pardillos Danielle Rousseau becomes Carmen Russo, the Italian actress that won the Spanish edition of Sobrevivientes 2006 (Survivors 2006), the reality show located precisely on a tropical island in which contestants competed to survive. On another page of Pardillos the presenter of the Dharma Initiative orientation video is Mercedes Mila, the host of the Spanish 
version of Big Brother. This kind of intertextual play is found throughout the comic and adds a further level of complexity to the narrative interpretation: to understand Pardillos it is not enough to be a faithful follower of Lost, the reader must also be steeped in Spanish mass culture and its characters. But Pardillos is not just a comic. Every episode/season of Pardillos is introduced by a video trailer that recaptures the aesthetic of the series, such as the original music or the fades to black or white. Pardillos, on the other hand, leads us to question the boundaries between user-generated content and the culture industry. What started as the webcomic of a college student ended up as a product that is distributed and sold through commercial channels.

This brief review of Lost's transmedia contents would be even more incomplete if we did not mention productions like Lost: The Official Magazine or the plastic figures of Lost characters. The company of the renowned artist Todd McFarlane - creator of Spawn, one of the most important comics of the 1990s produced in 2006 a first series of characters that continued in subsequent years. But the reader will ask at this point: But aren't we going too far? Can we really consider these plastic Barbie-like figures an extension of a narrative world?

\subsection{Videos}

In this category I include official videos - like The New Man In Charge, a nanotext released after the last episode of the sixth season, and the deleted scenes usually contained in the DVDs - and user-generated production. The Lost: Missing Pieces mobisodes may also be considered part of the official audiovisual content produced by the ABC. But the richest video production from a transmedia perspective has come from the fan culture.

If describing the official transmedia narrative is often a complicated task, then mapping the user-generated contents is downright impossible. In this section we will only look at a tiny part of Lost's user-generated contents, and focus on some audiovisual formats that can be considered as classic in the social media.

\subsubsection{Synchros}

Lost's narrative is very complex due to the large number of characters, the dense network of relationships established between them and the time (flashbacks/ flashforwards) and space (within/outside the island) fractures. After a couple of episodes the viewers must keep their cognitive encyclopedia (Eco 1979) in good shape to be able to catch the new information coming from the screen and integrate it into the interpretation process. 
Some prosumers have rebuilt specific key moments of the show and edited their own videos using a split-screen aesthetic popularized by other TV series like Fox's 24. Producing this kind of content is a complicated job as it requires, in addition to mastering the techniques of non-linear video editing, a careful review of the scenes and parallel assembly by matching all of them. One of the highlights of the series that has been most synchronized is the tragic crash of Flight 815. On the small screen viewers learned what each character was doing at the time of the accident after three or four seasons, but thanks to synchronized videos we can now see what was happening simultaneously (i.e., Lost: Flight 815 Crash in Real Time $\left.{ }^{4}\right)$.

\subsubsection{Recaps}

This kind of audiovisual content is a summary of previous episodes or seasons. This format is classic of Youtube videos (i.e., 9 Nine Minute Sopranos ${ }^{5}$ ) and always follows the same pattern: a voice-over recounts the events of history while passing fast images of the main scenes of each season. Many user-generated recaps do not have anything to envy to the official recaps produced by the majors (i.e., ABC's Lost in 8:156 or Lost recap - All You Need to Know About Lost in 4:247). Usergenerated recaps may include a soundtrack (i.e., Lost Season 1 Recap ${ }^{8}$ ) that suggests a new interpretation of the content. As in the previous case, to produce the recaps it is necessary to apply an advanced set of narrative, textual, and technological skills.

\subsubsection{Parodies}

Many prosumers love to disassemble their favorite show and remix it with other products to create new parodic interpretations. Lost has not been an exception: on YouTube and other video platforms it is possible to find hundreds of parodies and mashups inspired in the post-production philosophy (Bourriaud 2002; Scolari

4 http://www.youtube.com/watch?v=MKcKtjrL5bc (accessed 1 March 2013)

5 http://www.youtube.com/watch?v=AsgRwxx7au0 (accessed 1 March 2013)

$6 \mathrm{http}: / /$ www.youtube.com/watch?v=QIuXZ37GQIs (accessed 1 March 2013)

7 http://www.youtube.com/watch?v=rpc60JyAnl4 (accessed 1 March 2013)

8 http://www.youtube.com/watch?v=gP87MYOfWn8 (accessed 1 March 2013) 
2008a). ${ }^{9}$ For example, in their Lost parodies the Fine Brothers breathe life into the toy figures and remix the TV show characters with others from the world of film, TV, and sport. ${ }^{10}$ A typical Fine Brothers' parody usually begins with Lost characters discussing a topic - the voice-over accentuating the inflections of the real characters - until a "foreign" character, from Harry Potter to Gandalf, Jack Sparrow, Batman, The Joker or Michael Jordan, appears on the scene. In short, this is the same intertextual game played by Carlos Azaustre in Pardillos but in this case the external textual references are connected to global mass culture.

It should be noted that the Fine Brothers are not just simple prosumers but two young film and TV professionals that produce audiovisual contents for numerous companies. The aesthetics of their parodies, however, is marked by a low-cost style typical of many user-generated contents. As I explained above about Pardillos, the boundaries between the culture industry and user-generated productions are porous and flexible.

Another parody that we must include in this analysis is La Isla Presidencial (The Presidential Island), ${ }^{11}$ a project born in Venezuela that transforms Latin American presidents and King Juan Carlos of Spain into castaways after a nautical accident. In this case the Lost story becomes an excuse to take a sour look at Latin American political leaders. Even if the intertextuality of L I Isla Presidencial is mostly related to Lost, the parody also includes many other references like Cast Away (2000).

\subsubsection{Alternate endings}

Like many other blockbusters Lost has also generated user-generated alternate endings. For example in an alternate parodic ending Chuck Norris (Missing in Action from 1984) and the alien from Predator (1987) arrive at the mysterious island (i.e., Lost Alternate Ending ${ }^{12}$ ). Other alternate endings are not so parodic and propose a narrative extension involving the original characters of the series,

9 As Rose puts it:

the idea of people working together to "solve" or interpret a story at any scale beyond the water cooler is unprecedented, simply because no technology has enabled it before. Will it change storytelling? It already has. Inception, Lost - because its narrative was so convoluted, Lost implicitly demanded that people connect online to figure it out. No one ever dared do that on TV before. (Rose in Jenkins 2011)

$10 \mathrm{http}: / /$ www.thefinebrothers.com (accessed 1 March 2013)

$11 \mathrm{http}: / /$ islapresidencial.net (accessed 1 March 2013)

$12 \mathrm{http}: / /$ www.youtube.com/watch?v=E5PMZ-Xdse0 (accessed 1 March 2013) 
incorporating scenes from other films but maintaining a logical continuity with the plot of the TV show. In one of these alternate endings Jack Shephard apparently escapes from the island on a plane but later crashes during the landing. Jack is "unfolded" and attends his own death: one Jack dies on the stretcher in the emergency room while the other one goes out closing the door and his old life behind him (Lost Season 7 Alternate end / begin ${ }^{13}$ ). It is worth remembering that the first alternative endings of Lost were produced by the ABC at the end of the fourth season to avoid the risk of possible spoilers that could reduce the impact of the real ending.

\subsubsection{Re-cut trailers}

Another significant type of audiovisual user-generated content is the fake trailer, also called re-cut trailers. These remixed short videos announce a nonexistent movie or change the meaning of a film, for example the famous romantic comedy version of The Shining (1980) ${ }^{14}$ or the sequel to Titanic (1997). ${ }^{15}$ The fake trailers are very powerful tools for removing a work from a genre, repositioning it in another one and opening a broad spectrum of new interpretations. The fake trailer Lost: The Sitcom! Season I Intro, ${ }^{16}$ that presents the series as if it were a comedy, is a good example of this format.

A reflection before concluding this section: as we can see, the production of audiovisual user-generated contents is huge and the researcher risks getting lost in a complex geography of synchros, recaps, false trailers, alternate endings, and many other formats. This textual territory is still waiting for its explorers; we urgently need to adjust our analytical categories and create new taxonomies of these new narrative species.

\section{Transmedia narrative strategies}

If we look at the textual network that constitutes the transmedia fictional world of Lost we can identify different strategies of narrative expansion. In this Section I'll reflect on these strategies and propose a rhetorical classification for them.

13 http://www.youtube.com/watch?v=bEjtk4XnUdM (accessed 1 March 2013)

$14 \mathrm{http} / / /$ www.youtube.com/watch?v=sfout_rgPSA

15 http://www.youtube.com/watch?v=vD4OnHCRd_4 (accessed 1 March 2013)

16 http://www.youtube.com/watch?v=BPqxWQ-YfSO_(accessed 1 March 2013) 


\subsection{First reflections on cross-media strategies}

As we have seen, on one side we have the production of interstitial contents such as the Lost: Missing Pieces that fill in narrative blanks. These nanotexts bridge the gaps (ellipsis) in the sequence of events of the TV show. The creation of interstitial contents can be applied to any product, but obviously certain works are much easier to "farce" with nanotexts than others. For example Fox's 24, a series that presented 24 episodes in a single season corresponding to twenty-four hours in the "real" life of the main character, unleashed 364 days to fill with new contents (Scolari 2009a). In the case of Lost, and taking into account the growing complexity of the series as the seasons passed, all interstitial contents should fit perfectly into the narrative puzzle.

A variant of this expansive practice is to present events that happened before or after the diegetic time of the main text. In the case of Lost the discourse introduces this practice through flashbacks and flashforwards in the TV show, video games, and novels. Other fictional worlds, like Star Wars or 24, have fully exploited in novels or comics the idea of narrating events that occurred before or after the main audiovisual texts. As we have seen, these temporal expansions may be complemented with the compression of the narrative in the recaps (i.e., Lost: Flight 815 Crash in Real Time) or the official trailers and promos (i.e., Lost Season 6 Chessboard Promo ${ }^{17}$ ).

All of these practices may be placed into one single category: time-based transmedia strategies. These strategies act on the temporal dimension of the narrative, filling in the blanks, telling stories before or after the diegetic time of the main text or compressing the contents into a few minutes.

If we can describe a "time based" cross-media strategy it is not difficult to imagine a space-based transmedia strategy. In this second case the expansion affects the diegetic territory of the original text, for example the expansion of the CSI franchise from Miami to Las Vegas and NYC or some mobisodes of Fox's 24: "The contents for mobiles - for example, 24: Conspiracy and The Rookie - are situated a long way from the central axis: the first one is located in Washington, DC and the second includes only some of the characters from the TV show (and not Jack Bauer, the main character)" (Scolari 2009a: 598).

These productions are good examples of a space-based transmedia strategy. In the specific case of Lost I haven't identified non-parodic stories situated in other spaces. Parodic productions like Pardillos - situated on a "mysterious Mediterranean island" - or La Isla Presidencial - located on an island in front of the Brazilian coast - could be included in this strategy.

17 http://www.youtube.com/watch?v=eQ1HnEG4-is (accessed 1 March 2013) 
Another cross-media strategy used in Lost is the creation of new characters, providing them with their own narrative programs and making them interact with the characters already known, as happens in the video game Lost: Via Domus or in the novels Endangered Species, Secret Identity and Signs of Life. This strategy can be considered a classic of the culture industry and has been repeatedly employed by television and comics: a secondary character becomes independent and takes flight as a spin-off, for example the autonomization of Wolverine from the $X$-Men, Robin or Catwoman from Batman or Lucifer form The Sandman. These expansions can be integrated into a single strategy that could be defined as a characterbased transmedia strategy, an approach based on generating new characters.

Finally, another cross-media strategy identified in Lost is based on the creation of parodic paratexts. Parodies are a powerful tool for expanding the borders of a narrative world - they create a meta-narrative that dialogues with the original one and one of the favorite genres of user-generated contents. Even if parodies also integrate elements from the other strategies (e.g. Pardillos is situated on another island - space-based transmedia strategy - and La Isla Presidencial includes new characters - character-based transmedia strategy) I consider them to be so independent that they can be given their own specific category: parody-based transmedia strategy.

At this point we can reorganize the strategies and synthesize them in Table 1.

Table 1: Transmedia strategies. Classification based on time, space and character manipulations

\begin{tabular}{|c|c|c|}
\hline \multicolumn{2}{|c|}{ Transmedia strategies } & \multirow[b]{2}{*}{$\begin{array}{l}\text { Texts } \\
\text { Expansion: } \\
\text { - Lost: Missing Pieces (mobisode / interstitial nanotext) } \\
\text { - The New Man In Charge (not-seen-on-TV content), } \\
\text { - Lost Season 7 Alternate end / begin, Lost Alternate Ending } \\
\quad \text { (alternate ending) } \\
\text { Compression: } \\
\text { - Lost recap - All You Need to Know About Lost in 4:24 (recap) } \\
\text { - Lost: Flight } 815 \text { Crash in Real Time (synchronization) } \\
\text { - Lost Season 6 Chessboard promo (trailers/promo) }\end{array}$} \\
\hline on-parodic & Time-based & \\
\hline & Space-based & ------ \\
\hline & Character-based & $\begin{array}{l}\text { - Lost: Via Domus (video game) } \\
\text { - Bad Twin, Endangered Species, Secret Identity, Signs of Life } \\
\quad \text { (novels) }\end{array}$ \\
\hline Parodic & $\begin{array}{l}\text { Time-based } \\
\text { Space-based } \\
\text { Character-based }\end{array}$ & $\begin{array}{l}\text { - Lost: The Sitcom! Season I Intro (re-cut trailers) } \\
\text { - Pardillos } \\
\text { - Pardillos, La Isla Presidencial, Lost Parody \#7 - Batman }{ }^{18} \\
\text { (mashups) }\end{array}$ \\
\hline
\end{tabular}

18 http://www.youtube.com/watch?v=qj0wE593sJ8 (accessed 1 March 2013) 
Let's go further. These first reflections on cross-media strategies could be further developed and refined by applying categories from rhetoric. In the next paragraphs I'll attempt to formalize this taxonomy of expansion/compression transmedia strategies.

\subsection{Towards a rhetoric of transmedia narrative strategies}

Since classical rhetoric, the four fundamental rhetorical operations have been addition (adiectio), omission (detractio), transposition (transmutatio), and permutation (immutatio). Originally these four operations were called in Latin quadripartita ratio. Addition is based on the expansion of elements, omission on the subtraction of them, transposition or transferring changes the normal order or arrangement of the elements and, finally, permutation is based on the substitution of elements. In this rhetorical context all of the strategies presented in the previous section can be rearranged into a different schema. This new schema could be very useful for identifying not only expansion strategies but also narrative compressions; at the same time, these four rhetorical operations should not be reduced to cross-media strategies. In other words, we can expand or compress a narrative in the same media by adding or canceling out contents.

It is evident that the creation of interstitial contents or the expansion of the story by including events that happened before or after the main text could be considered an addition, in the same way that recaps or trailers are included in the category of omission. Lost: Missing Pieces are interstitial nanotexts that expand the diegetic world of the TV series, and parallel stories like Gary Trump's novel Bad Twins are also additions that enlarge the Lost fictional universe. Some specific alternate endings that continue the diegetic time of the TV series may also be included in this rhetorical operation. Trailers, promos and recaps cancel the textual excesses to create a synthesized nanotext; this narrative operation is based on the subtraction of elements, so they must be considered an omission.

Lost's continuous flashbacks and flashforwards are a good example of transposition, which works inside different media (TV, mobile devices, novels, and video games). If we look outside the television, the video synchronizations like Lost: Flight 815 Crash in Real Time are also examples of transposition: these videos show at the same time events that viewers have originally watched over different media and platforms over the years.

Finally, the rhetorical operation known as permutation can be found in parodies like Pardillos, a text based on substituting characters, companies and places (Danielle Rousseau $\rightarrow$ Carmen Russo, John Locke $\rightarrow$ Yon Locko, Pacific Island $\rightarrow$ 
Mediterranean Island, Oceanic Airlines $\rightarrow$ Naufragic Airlines, etc.) and in many re-cut trailers and alternate endings that mashup Lost with other productions. Most of the user-generated contents are found inside this rhetorical operation. The different transmedia strategies are synthesized in Table 2. ${ }^{19}$

Table 2: Transmedia strategies. Classification based on rhetorical operations

\begin{tabular}{|c|c|c|}
\hline $\begin{array}{l}\text { Transmedia } \\
\text { strategy }\end{array}$ & $\begin{array}{l}\text { Textual } \\
\text { format }\end{array}$ & Examples \\
\hline \multirow[t]{4}{*}{ Addition } & Interstitial nanotexts & - Lost: Missing Pieces (mobisodes) \\
\hline & $\begin{array}{l}\text { Before/after//parallel } \\
\text { stories }\end{array}$ & $\begin{array}{l}\text { - Bad Twin, Endangered Species, Secret Identity, } \\
\text { Signs of Life (novels) }\end{array}$ \\
\hline & Alternate endings & $\begin{array}{l}\text { - Lost season } 7 \text { Alternate end / begin (web video) } \\
\text { - Lost Alternate Ending (web video) }\end{array}$ \\
\hline & Extra contents & $\begin{array}{l}\text { - The New Man In Charge (web / DVD video } \\
\text { - ("never seen on TV") }\end{array}$ \\
\hline \multirow[t]{3}{*}{ Omission } & Recaps & - “Previously on Lost”(TV) \\
\hline & & $\begin{array}{l}\text { - Lost recap - All You Need to Know About Lost in } \\
\text { 4:24 (web video) }\end{array}$ \\
\hline & Trailers and promos & $\begin{array}{l}\text { - Lost Season } 6 \text { Chessboard promo (TV / web } \\
\text { video) }\end{array}$ \\
\hline \multirow[t]{3}{*}{ Transposition } & Flashbacks and & - Lost-Seasons 1 to 6 (TV) \\
\hline & flashforwards & - Novels, comics, video game, mobisodes, etc. \\
\hline & Synchronizations & - Lost: Flight 815 Crash in Real Time (web video) \\
\hline \multirow[t]{5}{*}{ Permutation } & Re-cut trailers & - Lost: The Sitcom! Season I Intro (web video) \\
\hline & Mashups & - La Isla Presidencial (web video animation) \\
\hline & & - Pardillos (web/printed comic) \\
\hline & & - Lost Parody \#7 - Batman (web video) \\
\hline & $\begin{array}{l}\text { Alternate endings } \\
\text { (mashups) }\end{array}$ & $\begin{array}{l}\text { - Lost season } 7 \text { Alternate end / begin (web video) } \\
\text { - Lost Alternate (web video) }\end{array}$ \\
\hline
\end{tabular}

19 In 1970 the Groupe $\mu$ reorganized the four rhetorical operations. They renamed transposition as omission-addition (for them it is just a succession of addition and omission operations) and, along with addition and omission, was categorized as a substantial operation. Permutation was categorized as a relational operation. The Groupe $\mu$ further developed this classification of rhetorical operations and distinguished between partial and complete omissions; simple or repetitive additions; partial, complete, or negative omission-additions; etc. This taxonomy could be very helpful in the future for expanding this initial classification of cross-media narrative strategies that I have presented in this article (Groupe $\mu$ 1981). 


\section{Conclusions}

How can we gain insight into the transmedia expansion and compression narrative strategies? The proposed taxonomy permits us to analyze and, above all, compare different transmedia narrative worlds. This analytical model, like any other theoretical construction, can be enriched and enhanced by applying it to other textual productions. In this context, we should not ignore the possible emergence of new strategies that would require us to improve the taxonomy proposed in this article.

Furthermore, this comparative work could help us to expand our knowledge of transmedia storytelling into other types of narrative, such as information. Do these transmedia strategies operate in, for example, news narrative? Only an analysis similar to the one proposed in this article could give us an answer to this question. The same may be said for different genres of fictional narratives: Do these transmedia strategies change from science fiction to comedy or thrillers?

Finally, the taxonomy can be easily applied by any professional interested in expanding (or reducing) a particular story across multiple media or platforms.

\subsection{On transmedia, paratexts and nanotexts: New challenges}

Where are the limits of transmedia storytelling? Does any paratext that has "something to do with the mother-text" automatically finish up in the transmedia drawer? I believe that we should begin to refine the range of our analytical categories if we really want to understand transmedia narratives. In short: not all the paratexts that sprout around a text necessarily form part of its narrative world.

I have described how texts like the recapitulations compress the fictional world. Should they be considered part of the transmedia textual galaxy? If we consider that transmedia storytelling is only an expansive narrative practice, them the recaps are automatically excluded from our analysis. However, if we consider that many recaps are produced by users, and in some cases they open new doors to the fictional world or introduce new textual components that expand our interpretation of the story, then they should be included in our analysis of transmedia storytelling.

Recaps present the same problem as adaptations. According to Jenkins "it is a matter of degree - since any good adaptation contributes new insights into our understanding of the work and makes additions or omissions which reshape the story in significant ways" (2009). In the case of recaps, it is also a "matter of degree.” The official recaps do not usually expand or introduce new elements into the story; however, some user-generated recaps do expand the possible interpre- 
tations of the story. Finally, recaps always propose new doors into the fictional world that allow new spectators to join the show. Therefore, it would be unwise to take recaps off our research agenda.

This proposal may sound contradictory. From a theoretical and conceptual perspective how can we include "compressed" texts in an "expansion strategy"? We should distinguish between the transmedia narrative world (a network of texts) and the individual texts. The transmedia textual network is expansive: it spreads from the core work (the TV series in the case of Lost) out to the neverending production of user-generated contents. However, the texts that compose the network can be either "expansive" or "compressed": in the first case they increase the narrative world by adding new situations or characters, and in the second case, they recapitulate portions of the narrative world to create new entrances, occasionally generating new interpretations. From a textual perspective it could be said that the narratives are like bellows that incorporate a double expansion/compression movement.

Another critical borderline is located on the frontier between transmedia storytelling and transmedia branding (Jenkins 2009). The Lost Experience and Find 815 show us that the boundaries between fiction and advertising are porous. In the same way that Lost flirts with all television genres (Jack's flashbacks take us to a traditional medical drama, Kate's to a thriller, Jin and Sun's to a soap opera, etc.; Tous 2010) the series also narrows the gap between marketing and fictional narrative strategies. This relationship has traditionally been expressed in the product-placement strategy (the presence of goods within the fiction, such as Apple or Dell computers in House, M.D. or Jack Bauer's Nokia phones in 24) but in Lost the fictional world is the brand (Scolari 2009a). On the other hand, we must remember that advertising has always been a transmedia experience: the combination of channels has been a basic feature of all advertisement campaigns throughout the twentieth century.

Nanotextualities occupy a central position in contemporary transmedia strategies. Interstitial contents like Lost: Missing Pieces and other nanotexts generated in the transmedia environment are well suited to the fragmented and fast consumption typical of mobile devices like iPods, iPhones, smartphones, etc. In a society characterized by an increasingly atomized economy of attention these nanotexts, the highest expression of the snack culture (Miller 2007), are like fish in water.

Specifically, the Lost: Missing Pieces expand and complement general scenes already seen on the television screen, but sometimes they also include important keys for understanding Lost's narrative world, for example when Jack's "father" tells the dog to wake his son up immediately after the plane crash (So It Begins released in the US on January 28, 2008). These nanotexts usually cannot be 
understood outside the main story: they are paratexts that require a viewer with a more or less profound knowledge of the mother-text. In this sense their autonomy is minimal. However, in some cases - such as we have just seen - the nanotexts can provide fundamental building blocks for understanding the narrative construction.

Two words about toy figures based on films, television series, and video game characters: this type of cultural product has never been investigated subspecies narrativa. Action figures are powerful narrative-construction devices. What do children do with their Indiana Jones, Harry Potter or Star Wars Lego and Playmobil figures? They tell stories. Maybe the first mashups of popular culture characters were not born on the web but in children's domestic scenarios where Batman and Indiana Jones fight Darth Vader in an eternal battle of injected plastic.

As Gray puts it:

The toys not only intensified several themes of the (Star War) films ... but also allowed individual children or communities of children playing together to personalize these themes, situating the child in the middle and as active participant ... not just as a distanced spectator ... The toys have never been "secondary" spin-offs or coincidental: they have played a vital role in, and thus have become a vital part of, the primary text and its unrivalled success. (Gray 2009: 183)

As mentioned above, both narratological and semiological approaches should get to work on a deeper analysis of the new formats, especially the short ones that I have defined as nanotexts. The knowledge accumulated by literature and film studies will be very useful for understanding these new narrative forms. Unfortunately, nanotextualities have only been recognized as a scientific object when they have been published in a book, while short audiovisual formats like mobisodes or Twittering often remain out of academic sight. On the other hand, semioticians must realize that we are facing transmedia narrative phenomena in which the construction of meaning is an integrated effect that arises from the articulation of texts in different languages and media. From an cultural perspective, the excellent quality of many recaps and synchros shows us that the borders between the culture industry and fan cultures are very blurry. There is a gray area where user-generated high-quality texts coexist with low-cost works produced by professionals.

\subsection{Flashforward: The End?}

Many Lost fans were disappointed with the last episode of the series. From the beginning it was clear that not all viewers would be satisfied with the show's 
conclusion. Lost fits perfectly into a subgenre that Piglia (1991) defined as paranoid fiction, that is, a story dominated by a conspiracy climate in the context of a continuous interpretative delirium. ${ }^{20}$

As we have seen in Section 2.2. the interpretation of the whole transmedia world of Lost (not just the TV show) is founded on collective intelligence. The construction of possible worlds (Eco 1979) and the creation of narrative hypotheses about the future development of a plot are basic elements of the interpretive process; Lost and many other transmedia productions demonstrate that nowadays this interpretive process is no longer an individual activity: possible worlds and hypotheses are built in online communities, in a technology-mediated global discussion. This radically new situation is a challenge to traditional semiotic theories, which are mainly based on the individual reading or watching experience (see note 9 ).

In the specific case of Lost, what should be a "normal" interpretation process has transformed into a frenetic search for the meaning of everything. Even the most standard ellipses of the narration must be fulfilled and explained. The army of Lost fans has developed an interpretive horror vacui: the dynamics of the plot spread a paranoid epidemic in which the consumers are always looking for new clues, hidden codes, and puzzles to solve from one coast to another of Lost's transmedia fictional world. From their perspective Lost is a complex network of Easter eggs waiting to be deciphered. Paranoid fiction.

If anything characterizes transmedia narratives it is that they tend to drag on into eternity and it is almost impossible to stop them. As much as J. J. Abrams and his team of writers have tried to finish it, Lost's narrative engine is still working. Transmedia storytelling teaches us that if producers don't want, don't know or can't generate new contents, prosumers will create and distribute them. You don't like Lost's ending? Create your own The End. DIY: Do It Yourself. In this context the new seasons of Lost are being cooked up in the social networks, in the conver-

20 In principle, we will deal with two elements, both in form and content, to define the concept of paranoid fiction. One is the idea of threat, the enemy, the enemies, the persecutor, the persecutors, the complot, the conspiracy, all that we can weave around this paranoid awareness, which is expanding this idea of the threat as a piece of that awareness.

The other important element in the definition of this awareness is the interpretative delirium, that is, the interpretation that erases the chance, to consider that nothing is accidental, that everything is due to a cause that may be hidden, which is a kind of encrypted message "directed to me." (Piglia 1991)

Translated into semiotic terms, Piglia's paranoid fiction is very close to Peirce's and Eco's unlimited semiosis. This invitation to unlimited semiosis and interpretive delirium is a characteristic of mastermind narrations (Clarke 2009: 124-126). 
sations of their fan tribes that continue the debate about alternative endings and hypothetical spin-offs that make them dream of a Seventh Season.

\section{References}

Abbot, Stacey. 2009. How lost found its audience: The making of a cult blockbuster. In Roberta Pearson (ed.), Reading Lost: Perspectives on a hit television show, 10-26. London: I.B. Tauris.

Abba, Tom. 2009. Hybrid stories: Examining the future of transmedia narrative. Science Fiction Film \& Television 2(1). 59-75.

Ankerberg, John \& Dillon Burroughs. 2007. What can be found in Lost?: Insights on God and the meaning of life from the popular TV series. Eugene: Harvest House.

Askwith, Ivan. 2009. "Do you even know where this is going?": Lost's viewers and narrative premeditation. In Roberta Pearson (ed.), Reading Lost: Perspectives on a hit television show, 159-180. London: I.B. Tauris.

Barra, Luca, Cecilia Penati \& Massimo Scaliglioni. 2010. Estension, accesso, brand. Le tre dimensioni della televisione convergente. In Aldo Grasso \& Massimo Scaglioni (eds.), Televisione convergente. La TV oltre il piccolo schermo, 21-32. Milan: LinkRicerca.

Brooker, Will. 2009. Television out of time: Watching cult shows on download. In Roberta Pearson (ed.), Reading Lost: Perspectives on a hit television show, 51-72. London: I.B. Tauris.

Bourriaud, Nicolas. 2002. Postproduction: Culture as screenplay. How art reprograms the world. New York: Lukas \& Sternberg.

Cascajosa, Concepción. 2006. "Perdidos," símbolo de una nueva estrategia de marketing. http://www.vayatele.com/ficcion-internacional/perdidos-simbolo-de-una-nuevaestrategia-de-marketing (accessed 1 March 2013).

Clarke, M. J. 2009. Lost and mastermind narration. Television and New Media 11(2). 123-142.

Dena, Chris. 2008a. Techniques for segmenting content. http://www.christydena. com/2008/09/techniques-for-segmenting-content-across-media (accessed 1 March 2013).

Dena, Chris. 2008b. Emerging participatory culture practices: Player-created tiers in alternate reality games. Convergence $14.41-57$.

Dwyer, Tim. 2010. Media convergence. Maidenhead: McGraw Hill.

Eco, Umberto. 1979. Lector in fabula. Milan: Bompiani.

González-Alarcón, Sandra \& Lluís Anyó. 2009. Experiencia fan en la cultura digital: El caso de Perdidos. Paper presented at the $V$ Congrés Internacional Comunicació i realitat. La metamorfosi de l"espai mediàtic, Barcelona, May 22-23. http://grups.blanquerna.url. edu/narrativamultimedia/fanperdidos.pdf (accessed 18 July 2010).

Gómez Alonso, Rafael. 2008. Aportaciones teóricas en los relatos televisivos: El caso de Lost. Enlaces 8. http://dialnet.unirioja.es/servlet/articulo?codigo=2578689 (accessed 1 March 2013).

Grainge, Paul. 2009. Lost logos: Channel 4 and the branding of American event television. In Roberta Pearson (ed.), Reading Lost: Perspectives on a hit television show, 95-115. London: I.B. Tauris.

Gray, Jonathan. 2009. Show sold separately: Promos, spoilers, and other media paratexts. New York: New York University Press. 
Greimas, Algirdas. 1987. On meaning: Selected writings in semiotic theory. London: Frances Pinter.

Groupe $\mu$. 1981. A general rhetoric. Baltimore, MA: Johns Hopkins University Press.

Hill, Dan. 2006. Why Lost is genuinely new media. http://www.cityofsound.com/blog/2006/03/ why_lost_is_gen.html (accessed 1 March 2013).

Jenkins, Henry. 2003. Transmedia storytelling: Moving characters from books to films to video games can make them stronger and more compelling. Technology Review. http://www.technologyreview.com/biotech/13052/ (accessed 1 March 2013).

Jenkins, Henry. 2006a. Fans, bloggers, and gamers: Exploring participatory culture. New York: New York University Press.

Jenkins, Henry. 2006b. Convergence culture: Where old and new media collide. New York: New York University Press.

Jenkins, Henry. 2009. The revenge of the origami unicorn: Seven principles of transmedia storytelling. http://henryjenkins.org/2009/12/the_revenge_of_the_origami_uni.html \& http://henryjenkins.org/2009/12/revenge_of_the_origami_unicorn.html (accessed 1 March 2013).

Jenkins, Henry. 2011. Deep media, transmedia, what's the difference? An Interview With Frank Rose (part one). http://henryjenkins.org/2011/01/deep_media_transmedia_whats_ th.html (accessed 1 March 2013).

Johnson, Dereck. 2009. The fictional institutions of Lost: World building, reality and the economic possibilities of narrative divergence. In Roberta Pearson (ed.), Reading Lost: Perspectives on a hit television show, 27-49. London: I.B. Tauris.

Jones, Steven. 2007. Dickens on Lost: Text, paratext, fan-based media. Wordsworth Circle 38(1-2). 71-78.

Jones, Steven. 2008. The meaning of video games: Gaming and textual strategies. New York: Routledge.

Kelly, Kevin \& Paula Parisi. 1997. Beyond Star Wars (interview with George Lucas). Wired 5(02). http://www.wired.com/wired/archive/5.02/fflucas.html (accessed 1 March 2013).

Kim, Jeffrey, Elin Lee, Timothy Thomas \& Caroline Dombrowski. 2009. Storytelling in new media: The case of alternate reality games, 2001-2009. First Monday 14(6). http://www.uic.edu/ htbin/cgiwrap/bin/ojs/index.php/fm/article/view/2484/2199 (accessed 1 March 2013).

Lavery, David. 2009. Lost and long-term television narrative. In Pat Harrigan \& Noah WardripFruin (eds.), Third person: Authoring and exploring vast narratives. Cambridge, MA: MIT Press.

Long, Geoffrey. 2007. Transmedia storytelling: Business, aesthetics, and production at the Jim Henson company. Cambridge: Massachusetts Institute of Technology MA thesis.

Miller, Nancy. 2007. Minifesto for a New Age. Wired 15(03). http://www.wired.com/wired/ archive/15.03/snackminifesto.html (accessed 1 March 2013).

Mittel, Jason. 2006. Narrative complexity in contemporary American television, The Velvet Light Trap 58. https://seguecommunity.middlebury.edu/view/html/site/jmittell/node/4230077 (accessed 1 March 2013).

Mittel, Jason. 2009. Lost in a great story: Evaluation in narrative television (and television studies). In Roberta Pearson (ed.), Reading Lost: Perspectives on a hit television show, 119-138. London: I.B. Tauris.

Ndalianis, Angela. 2009. Lost in genre: Chasing the white rabbit to find a white polar bear. In Roberta Pearson (ed.), Reading Lost: Perspectives on a Hit Television Show, 181-197. London: I.B. Tauris. 
Pearson, Roberta. 2009. Chain of events: Regimes of evaluation and Lost's construction of the televisual character. In Roberta Pearson (ed.), Reading Lost: Perspectives on a hit television show, 139-158. London: I.B. Tauris.

Piglia, Ricardo. 1991. La ficción paranoica. http://www.elinterpretador.net/35/movil/piglia/ piglia.html (accessed 15 June 2010).

Roig, Antoni. 2010. Cine en Conexión. Producción Industrial y Social en la Era "Cross-media." Barcelona: UOC Press.

Scolari, Carlos A. 2008a. Alrededor de la(s) convergencia(s). conversaciones teóricas, divergencias conceptuales y transformaciones en el ecosistema de medios. Signo y Pensamiento 28. 44-55.

Scolari, Carlos A. 2008b. Hipermediaciones. Elementos para una teoría de la comunicación digital interactiva. Barcelona: Gedisa.

Scolari, Carlos A. 2009a. Transmedia storytelling: Implicit consumers, narrative worlds, and branding in contemporary media production. International Journal of Communication 3. 586-606.

Scolari, Carlos A. 2009b. Mapping conversations about new media: The theoretical field of digital communication. New Media \& Society 11. 943-964.

Scolari, Carlos A. 2009c. The grammar of hypertelevision: An identikit of the convergence age television (or how television is simulating new interactive media). Journal of Visual Literacy 28(1). 28-49.

Smith, Aaron. 2009. Transmedia storytelling in television 2.0. http://blogs.middlebury.edu/ mediacp/ (accessed 1 March 2013).

Tous, Anna. 2010. La era del drama en televisión. Perdidos, CSI: Las Vegas, El Ala Oeste de la Casa Blanca, Mujeres Desesperadas y House. Barcelona: UOC Press.

Whitney, Daisy. 2009. "Lost," "SNL," "Grey”s" tops in online viewing, Nielsen says. http:// www.tvweek.com/news/2009/02/lost_snl_greys_tops_in_online.php (accessed 1 March 2013).

\section{Bionote}

Carlos A. Scolari (b. 1963) is a professor at the Universitat Pompeu Fabra 〈carlosalberto.scolari@upf.edu〉. His research interests include semiotics of interfaces and HCI, theories of digital interactive communication, media ecology, and transmedia storytelling. His publications include "Digital Eco_Logy: Umberto Eco and a semiotic approach to digital communication" (2009); "Desfasados: Las formas de conocimiento que estamos perdiendo, recuperando y ganando" (2009); "The sense of the interface: applying Semiotics to HCI research" (2009); and "Media ecology: Map of a theoretical niche" (2010). 